\title{
A Methodology for a Comprehensive Probabilistic Tsunami Hazard Assessment: Multiple Sources and Short-Term Interactions
}

\author{
Grezio Anita ${ }^{1, *}$, Roberto Tonini ${ }^{2}$, Laura Sandri ${ }^{1}$, Simona Pierdominici ${ }^{3}$ and Jacopo Selva $^{1}$ \\ ${ }^{1}$ Istituto Nazionale di Geofisica e Vulcanologia, sezione di Bologna, Via Franceschini 31, \\ 40128 Bologna, Italy; E-Mails: laura.sandri@ingv.it (L.S.); jacopo.selva@ingv.it (J.S.) \\ ${ }^{2}$ Istituto Nazionale di Geofisica e Vulcanologia, Via di Vigna Murata 605, 00143 Roma, Italy; \\ E-Mail: roberto.tonini@ingv.it \\ ${ }^{3}$ Helmholtz Centre Potsdam, GFZ German Research Centre for Geosciences, Potsdam 14473, \\ Germany; E-Mail: pierdo@gfz-potsdam.de
}
* Author to whom correspondence should be addressed; E-Mail: anita.grezio@ingv.it ; Tel.: +39-051-4151475; +39-051-4151499.

Academic Editor: Valentin Heller

Received: 22 August 2014 / Accepted: 18 December 2014 / Published: 15 January 2015

\begin{abstract}
We propose a methodological approach for a comprehensive and total probabilistic tsunami hazard assessment (TotPTHA), in which many different possible source types concur to the definition of the total tsunami hazard at given target sites. In a multi-hazard and multi-risk perspective, the approach allows us to consider all possible tsunamigenic sources (seismic events, slides, volcanic eruptions, asteroids, etc.). In this respect, we also formally introduce and discuss the treatment of interaction/cascade effects in the $\operatorname{TotPTHA}$ analysis and we demonstrate how the triggering events may induce significant temporary variations in short-term analysis of the tsunami hazard. In two target sites (the city of Naples and the island of Ischia in Italy) we prove the feasibility of the TotPTHA methodology in the multi-source case considering near submarine seismic sources and submarine mass failures in the study area. The TotPTHA indicated that the tsunami hazard increases significantly by considering both the potential submarine mass failures and the submarine seismic events. Finally, the importance of the source interactions
\end{abstract}


is evaluated by applying a triggering seismic event that causes relevant changes in the short-term TotPTHA.

Keywords: submarine seismic source; submarine mass failure; triggering event; sources interactions; long- and short-term hazard; Naples-Ischia; PTHA

\section{Introduction}

In recent years the Probabilistic Tsunami Hazard Assessment (PTHA) has been proposed in different areas of the globe using different methodologies that can be grouped in:

(a) scenarios ([1-4]);

(b) statistical evaluations of the historical earthquakes ([5-8]);

(c) statistical analysis of tsunami sources ([9-11]);

(d) Bayesian inferences ([12-14].

In $(a)$, the sources are generally identified a priori, neglecting the aleatory uncertainties on tsunami sources. In $(b)$, the probability strongly depends on the catalogue completeness and data availability. In $(c, d)$, the aleatory uncertainty of the sources is considered predominant so that the study is focused on the random nature of the tsunami generation due to the intrinsic unpredictability of the event occurrence. Also, the epistemic uncertainty is often treated explicitly merging many information into a single statistical model through Logic Trees or Bayesian inference, as recently proposed for the cases $(b-d)$.

Most of the PTHAs focus on one single type of tsunami source, usually the seismic sources $([9,10,15,16])$. However, it has been demonstrated that in many areas, major causes of tsunami are the non-seismic sources, such as mass failures (whether or not triggered by seismic events) ([17,18]), volcanic activity ([19-25]). In particular, volcanic flows ([26,27]), landslides and rock slides on coastal areas ([28-32]) and submarine mass failures ([33-36]) may lead to the catastrophic tsunamis, but very few analyses treated such non-seismic tsunamigenic sources in a probabilistic frame $([13,37])$. Meteorite impacts can also trigger tsunamis, even though they are extremely rare events ([38]).

In order to provide an unbiased and a complete PTHA, all possible tsunami sources should be considered and combined together and their relative importance properly quantified.

Also, in PTHA a bias may be induced by neglecting an external event that is not significant for tsunami generation but is able to activate another type of tsunamigenic source. This external event is commonly defined a triggering event. Formally including all possible interaction chains, triggers and cascade effects would make the number of conditional hazards to be assessed too large and neither large databases nor theoretical background are available in those cases. As a result, the underestimation of source interactions could result in an underestimation of the hazards. Thus, several simplifications are needed, such as: $(i)$ reducing the analysis to few significant event types; or $(i i)$ considering several 
single specific cascade scenarios. In case $(i)$ a triggering event may be the volcanic unrest (deformations may produce tsunamigenic landslides), or coastal/submarine earthquakes (that may cause tsunamigenic earthquakes, or landslides); In case ( $i i)$ the occurrence of one event possibly affects another hazard.

Multi-hazard and multi-risk assessments are new approaches $([39,40])$ that allow the comparison of different hazards and risks and their interactions, accounting for multiple events that may exponentially increase the impact of disasters on society. Both the comparison of different sources and the interaction/cascade effects are among the most important factors of multi-hazard and multi-risk assessments, as treated in several recent analyses $([39,41])$. In this perspective, the PTHA represents a multi-source problem because of the different type of sources (earthquakes, landslides and volcanic eruptions) to be considered in a multi-risk framework (natural, industrial, nuclear, coastal infrastructure risk) since consequences are highly impacting.

Indeed, a multi-source approach for PTHA is fundamental for an unbiased and a complete analysis. Firstly, in the present paper we indicate how to simultaneously deal with different types of tsunamigenic sources in a coherent probabilistic framework by proposing a comprehensive method to provide a Total Probabilistic Tsunami Hazard Assessment (TotPTHA) and evaluating the representativeness of the used tsunamigenic source dataset/catalogue.

Secondly, we pose the problem of interaction/cascade effects considering when they may play a major role in TotPTHA and how to estimate them in short- and long term assessments.

Finally, the applicability of the TotPTHA methodology is exemplified for the city of Naples and the Island of Ischia (Italy), accounting for (1) different types of sources (multi-source approach); and (2) specific triggering event (source interaction approach).

\section{A Comprehensive TotPTHA Methodology}

The TotPTHA indicates the comprehensive PTHA in a given target location. Here, the term "comprehensive" means an exhaustive tsunami hazard assessment based on datasets including all sources. In the present methodology the TotPTHA formally merges the PTHAs due to all different types of tsunamigenic sources. The TotPTHA is defined as the probability that in a given exposure time $\Delta t$ a selected value $z$ of a tsunami parameter $Z$ is overcome by any possible tsunamigenic source

$$
\operatorname{TotPTH} A \Rightarrow p(Z \geq z, \Delta t)
$$

In Equation (1), the tsunami parameter $Z$ can be referred to any parameter describing the tsunami characteristics and intensity. It can be run-up, velocity, energy, moment flux, wave height, or any other variable required by the tsunami hazard/vulnerability/risk assessment.

Previous studies treated the different possible types of tsunamigenic sources separately, producing a PTHA in a specific region, with special emphasis on one type of source, generally the seismic one. If only one type of source is taken into account then only a portion of the total number of tsunamis is considered, leading to a bias in the PTHA analysis due to the neglected types of tsunamigenic sources. This relates to the issue on whether non-seismic sources (or the "non-prevalent" tsunamigenic source) can be ignored.

For example, in a global analysis, about $75 \%$ of the historical tsunami are generated by seismic sources and the remaining $25 \%$ by non-seismic ones (mass failure, volcanic, meteorological, 
cosmogenetic, and anthropogenic sources) ([42]). Such proportion may drastically change in a particular area where the hazard posed by non-seismic sources is significant. Also, tsunami events generated by non-seismic causes often have a more devastating impact in near-field areas compared to the tsunami caused by seismic sources.

\subsection{TotPTHA: The Effects of Multiple Source Types of dIfferent Potentially Tsunamigenic Source Events}

In the present study, the term Source Type $(S T)$ indicates a selected set of potentially tsunamigenic sources (e.g., source types refer to submarine seismicity, mass failures, volcanic activity, meteorite impacts, etc.), and the term Source Event $(S E)$ indicates a potentially tsunamigenic event of a specific source type (e.g., a given submarine earthquake with specific fault parameters, magnitude and location).

Given a specific $i$-th tsunamigenic source type $S T_{i}$ the relative $P T H A_{i}$ indicates the contribution to the TotPTHA

$$
P T H A_{i} \Rightarrow p\left(Z \geq z, S T_{i} ; \Delta t\right)=p\left(Z \geq z \mid S T_{i}\right) p\left(S T_{i}, \Delta t\right)
$$

The specific contribution $P T H A_{i}$ can be isolated by conditioning the TotPTHA with respect to the occurrence of the specific $S T_{i}$.

For example, in the case of seismic sources it is

$$
\begin{aligned}
p(Z \geq z, \Delta t) & =p\left(Z \geq z, E_{q} s ; \Delta t\right)+p\left(Z \geq z, \bar{E}_{q} s ; \Delta t\right) \\
& =p\left(Z \geq z \mid E_{q} s\right) p\left(E_{q} s, \Delta t\right)+p\left(Z \geq z \mid \bar{E}_{q} s\right) p\left(\bar{E}_{q} s, \Delta t\right)
\end{aligned}
$$

where $E_{q} s$ means earthquakes and $S T_{i} \equiv E_{q} s$. The first addend (denoted by $E_{q} s$ ) takes into account the tsunamis caused only by earthquakes and the second one (denoted by $\bar{E}_{q} s$ ) the tsunamis occurred even though earthquakes do not occur (i.e., tsunamis generated by different $S T \mathrm{~s}$ ).

Locally, the $P T H A_{i}$ due to earthquakes can be considered equivalent to the TotPTHA if, and only if, in Equation (3) the non-earthquake $p\left(Z \geq z, E_{q} s ; \Delta t\right)$ is negligible respect to the earthquake $p\left(Z \geq z, E_{q s} ; \Delta t\right)$. This may happen if we assume negligible the probability of occurrence of the other $S T$ s (the term $p\left(\bar{E}_{q s}, \Delta t\right) \simeq 0$ ) and/or the probability of overcoming the selected parameter $z$ due the other $S T$ s (the term $p\left(Z \geq z \mid \bar{E}_{q s}\right) \simeq 0$ ).

In general, the TotPTH $A$ may be expressed by

$$
p(Z \geq z, \Delta t)=1-\prod_{i=1}^{N_{T O T}}\left[1-p\left(Z \geq z, S T_{i} ; \Delta t\right)\right]
$$

where the product over the $N_{T O T}$ types of tsunamigenic $S T_{i}\left(i=1, \ldots, N_{T O T}\right)$ represents the probability that none of the $S T$ s produces a value of the tsunami parameter $Z$ larger than $z$ in $\Delta t$. This formulation assumes that the occurrences of the $Z$ values generated by different $S T$ s are mutually independent. This assumption of independence is valid also considering that: 
(a) the propagations of different tsunami waves are independent in the case of almost simultaneous events,

(b) the sizes of different $S T$ s are independent in the case of triggering events (see paragraph 2.2), and

(c) the PTHAs are relative to the next main tsunami event and possible subsequent tsunamis are not included (similarly to other hazard assessments: aftershocks are not examined in PSHAs, [43], or subsequent eruptions are not encompassed in PVHAs, [44]).

In fact, when one significant tsunami event occurs many factors characterizing the system (morphology of the coasts, bathymetry, exposure, etc.) might change and the previous hazard/ vulnerability/risk assessments should be updated. For this reason, sequences of tsunami waves immediately after a major tsunami event should be excluded by the PTHAs and eventually removed from the catalogues ([45]). In contrast, the cascade effects should be examined for each $S T$ under the assumption that a triggering event may not produce any tsunami (even if potentially tsunamigenic) but its tsunamigenic potential may be assessed on the basis of the triggered event only.

We calculate the TotPTHA through Equation (4) by evaluating separately each PTHA from the different $S T_{i}$. As a special case, the Equation (4) can represent a single tsunamigenic $S T$ if we set $N_{T O T}=1$. Then, the TotPTHA is equivalent to the PTHA $A_{i}$ of Equation (2). In the example of Equation (3) for the seismic sources, a bias would be introduced by neglecting the second addend of the equarion.

Each $i$-th $S T_{i}$ can be represented by a sufficient large number $N_{i}$ of independent physical sources. The $j$-th $S E$ relative to the $i$-th $S T$ is indicated by $S E_{i j}$ and the correspondent $P T H A_{i}$ is given by

$$
p\left(Z \geq z, S T_{i} ; \Delta t\right)=1-\prod_{j=1}^{N_{i}}\left[1-p\left(Z \geq z, S E_{i j} ; \Delta t\right)\right], i=1, \ldots, N_{\text {TOT }}
$$

In the seismic example, $S E_{i j}$ is the $j$-th specific earthquake event of given location, size and magnitude relative to the $i$-th type, that is the seismic one.

The underlying assumptions of Equation (5) are essentially the same of Equation (4) and the final TotPTH A is obtained by substituting Equation (5) in Equation (4)

$$
p(Z \geq z, \Delta t)=1-\prod_{i=1}^{N_{T O T}} \prod_{j=1}^{N_{i}}\left[1-p\left(Z \geq z, S E_{i j} ; \Delta t\right)\right]
$$

The total number of sources is $\sum_{i=1}^{N_{T O T}} N_{i}$, that is the sum of $N_{T O T}$ sets of tsunamigenic source types $S T_{i}$ (seismic, mass failure, volcanic, meteorologic, cosmogenetic, anthropogenic) and each set is defined by $N_{i}$ tsunamigenic source events $S E_{i j}$. In Equation (6) each $p\left(Z \geq z, \Delta t ; S E_{i j}\right)$ represents the PTHA relative to a single independent tsunamigenic physical source and is expressed by

$$
p\left(Z \geq z, S E_{i j} ; \Delta t\right)=p\left(Z \geq z, \mid S E_{i j} ; \Delta t\right) p\left(S E_{i j}, \Delta t\right)
$$

The factors $p\left(S E_{i j}, \Delta t\right)$ and $p\left(Z \geq z \mid S E_{i j}\right)$ may be related respectively to the "source phase" and the "inundation phase" of a tsunami event. This formulation is useful to separate the temporal occurrence of tsunami sources (evaluated often by Poisson models, [46]) from the tsunami impacts (simulated usually by scenario models, [47]). 


\subsection{Source Interactions and Triggering Events}

Equations (6) and (7) are useful to consider possible triggers on sources and their interactions. The term Source Interaction $S I$ is referred to the interaction process that may produce an extended set of potential events either tsunamigenic or non-tsunamigenic. The triggering event $T E$ is a specific event of the extended set and it belongs to the same $S T$ or a different $S T$.

For example, cases of $S I$ s occur when slides are generated by earthquakes or eruptions. A case of $T E$ is referred to: a specific volcanic eruption, that triggers an earthquake or landslide; an earthquake, that triggers another earthquake or landslide; a volcanic unrest episode that triggers an earthquake or landslide.

Given the hypotheses of Equations (4) and (6), even potentially tsunamigenic events may not generate tsunami. Thus, we can state that a generic event (tsunamigenic or not) may trigger another tsunamigenic event by only acting on the source phase in Equation (7). Also, all STs must be assumed independent in Equations (4) and (7), when one triggering event $T E$ (or a set of independent $T E$ s) occurs. In practice, each single source probability $p\left(S E_{i j}, \Delta t\right) \forall i, \forall j$ can be updated in Equation (7) accounting for the occurrence of the $T E$. Then, the updated source probabilities can be used in Equation (6) to assess the TotPTHA.

Given a specific $k$-th triggering event $T E$ the probability of occurrence of the specific $S E_{i j}$ due to the occurrence of the $T E_{k}$ is

$$
p\left(S E_{i j}, T E_{k} ; \Delta t\right)=p\left(S E_{i j} \mid T E_{k}\right) p\left(T E_{k}, \Delta t\right)
$$

Assuming that the $S I \mathrm{~s}$ may produce different and independent $T E \mathrm{~s}$, the cumulated effect of all $N_{T E}$ possible $T E$ s is

$$
\begin{aligned}
p\left(S E_{i j}, T E_{1}, \ldots, T E_{N_{T E}} ; \Delta t\right) & =1-\prod_{k=1}^{N_{T E}}\left[1-p\left(S E_{i j} \mid T E_{k}\right) p\left(T E_{k}, \Delta t\right)\right] \\
& \approx \sum_{k=1}^{N_{T E}} p\left(S E_{i j} \mid T E_{k}\right) p\left(T E_{k}, \Delta t\right)
\end{aligned}
$$

where the approximation holds if $p\left(S E_{i j} \mid T E_{k}\right) \ll 1$ and the terms of order higher than 2 are neglected. The interaction matrix $p\left(S E_{i j} \mid T E_{k}\right)$ represents the interactions among the different events and the terms of order higher than 2 in this matrix are related to a chain of interactions and triggering events. For example, the probability of occurrence is neglected in the case of a volcanic eruption that triggers an earthquake that triggers a slide that causes a tsunami (cascade of events).

We define $p^{*}\left(S E_{i j}, \Delta t\right)$ the total probability of occurrence of the $S E_{i j}$ in the time interval $\Delta t$ due to its intrinsic probability of occurrence and to a possible $S I$

$$
\begin{aligned}
p^{*}\left(S E_{i j}, \Delta t\right) & =p\left(S E_{i j}, \Delta t\right)+\left[1-p\left(S E_{i j}, \Delta t\right)\right] p\left(S E_{i j}, T E_{1}, \ldots, T E_{N_{T E}} ; \Delta t\right) \\
& \approx p\left(S E_{i j}, \Delta t\right)+p\left(S E_{i j}, T E_{1}, \ldots, T E_{N_{T E}} ; \Delta t\right)
\end{aligned}
$$

The approximation is possible since non-interactive source probabilities are usually $\ll 1$, then $\left(1-p\left(S E_{i j}, \Delta t\right)\right) \approx 1$. We underline that Equation $(10)$ is based on two fundamental assumptions:

(1) the triggering mechanisms are independent, meaning that two or more $T E$ s sum their effects in term of probability, but the combined effects do not result in a further amplification of the tsunami parameters at the coast;

(2) only first order interactions are modeled and second order (or higher) are assumed negligible. 
We substitute the source phase probability $p^{*}\left(S E_{i j}, \Delta t\right)$ of Equation (10) for the non-interactive probability $p\left(S E_{i j}, \Delta t\right)$ of Equation (6). Finally, using the updated probability of Equation (7) we evaluate the $S I$ effects due to all $S T$ s and assess the TotPTHA.

\subsection{Catalogue Completeness and Source Representativeness}

In general, the completeness analysis consists of a screening of the data collected in a database/catalogue in order to evaluate the degree of representativeness of the real system and the influence of the missing information on the final assessment. In many cases, the tsunami catalogues are much less complete than other catalogues (for example the seismic catalogues) and this plays a fundamental role in hazard assessment. In fact, $(i)$ small datasets imply a high level of uncertainties and $(i i)$ non-representative datasets may introduce important biases in the results (to be compensated by other means). Indeed, those aspects pose an intrinsic limitation when a database/catalogue of rare source events is used for probabilistic hazard assessments because it is not adequate to explore the whole potential aleatoric variability.

Now we consider the problem of the representativeness of the subset of the innumerable possible sources (in the cases of $S E \mathrm{~s}, S T \mathrm{~s}, T E \mathrm{~s}$ ) and we discuss the unbiased PTHA, assuming a certain completeness of the available catalogues of the past events.

- Source representativeness ( $\left.S E_{\text {repres }}\right)$

It is related to the fact that some $S E$ s of a given $S T$ may be not considered in the PTHA. Given a set of $S E_{i j}$, we may evaluate the source representativeness for the target site computing $M_{1} / T_{1}$, where $M_{1}$ is the number of tsunamis generated by the $S E_{i j}$ and $T_{1}$ is the total number of tsunamis due to that $S T$.

For example, in the case of the seismic $S T$ let us assume that the sources $S E_{i j}$ ( $i=$ earthquakes, and $j=1, \ldots, N_{i}$ numbers of events) are located in a delimited study area at given distance from a target site. In this case, the most distant seismic sources are neglected and only near sources are assumed representative of all seismic sources, meaning that the PTHA cannot be influenced by far earthquakes. However, tsunami are known to travel long distances and excluding far-field sources may lead to underestimations of the tsunami hazard. $M_{1}$ is the number of tsunamis from seismic sources belonging to the study area and $T_{1}$ the total number of tsunamis due to the earthquakes. If the ratio $M_{1} / T_{1}$ is close to 1 , we might have chosen a good subset of all possible $S E$ s of the $S T_{i}$ to evaluate the PTHA at the target site. For simplicity in the example we assume that all sources are well represented with respect to one source parameter, that is the location. In a complete discussion, the source representativeness should include all other parameters describing the source (magnitude, depth, focal mechanism, fault geometry).

- Source-type representativeness ( $\left.S T_{\text {repres }}\right)$

In this case, several $S T$ s may be neglected in the PTHA. A source-type representativeness can be estimated by $M_{2} / T_{2}$ where $M_{2}$ is the number of tsunami events at the target sites as reported by catalogues and and $T_{2}$ is the total number of tsunami events from any possible $S T$. 
For example, in the case of different $S T$ s like earthquakes, submarine mass failures and eruptions we need to evaluate the bias introduced by neglecting sub-aerial slides and meteorites. If the number $M_{2} / T_{2}$ is close to 1 , it is reasonable to neglect other $S T$ s.

- Interaction-source representativeness ( $\left.T E_{\text {repres }}\right)$

The interactions of the sources may significantly modify the PTHA, especially in short-term applications. This implies that if one (among many) interaction-source is not considered, the resulting $P T H A$ is biased.

An interaction-source representativeness can be formulated by $M_{3} / T_{3}$, where $M_{3}$ is the number of tsunami due to cascade effects known by experimental or modeled interaction-source cases, and $T_{3}$ the total number of all possible tsunami. However, this ratio is subject to underestimation, since the identification of all the interactions is difficult and in many cases the evaluation of $T_{3}$ may be subjective $([39,40])$.

\subsection{Source Interactions in Long- and Short-Term TotPTHA}

In the long-term hazard assessments it is common to consider the $\Delta t$ of order of years/decades. In the short-term hazard assessments the $\Delta t$ is of order of hours/days/weeks/months.

The effects of the $S I$ s are automatically included into the estimation of the source probability in long-term hazard assessments based on catalogues of the past $S E$ occurrence. For example, this is the case of the undifferentiated catalogues of the seismic sources. Also, in the tsunami catalogues the interaction episodes are usually included, and thus $p^{*}\left(S E_{i j}, \Delta t\right)$ is directly estimated using the past occurrence of the TEs. However, such interaction effects may be not present in long-term applications if the analysis is based on a single type of source. This analysis can be supposed unbiased only if the probability $p\left(S E_{i j}, \Delta t ; T E_{1}, \ldots, T E_{N_{T E}}\right)$ is assumed negligible with respect to the non-interactive source probability in Equation (9)

$$
\sum_{k=1}^{N_{T E}} p\left(S E_{i j} \mid T E_{k}\right) p\left(T E_{k}, \Delta t\right) \ll p\left(S E_{i j}, \Delta t\right)
$$

If $p\left(T E_{k}, \Delta t\right) \approx p\left(S E_{i j}, \Delta t\right)$ and $p\left(S E_{i j} \mid T E_{k}\right) \ll 1 \forall i$, for each specific $T E_{k}$ in Equation (11), then the standard non-interactive $p\left(S E_{i j}, \Delta t\right)$ can be used for the long-term tsunami hazard assessment in Equation (7)

$$
p\left(S E_{i j}, \Delta t\right) \Rightarrow \operatorname{TotPTH} A_{\text {long-term }}
$$

If the specific $T E_{k}$ occurs, then the probability $p\left(T E_{k}, \Delta t\right)$ is $\approx 1$ and the approximation in Equation (11) is not valid. Indeed, $p^{*}\left(S E_{i j}, \Delta t\right)$ should replace $p\left(S E_{i j}, \Delta t\right)$ in Equation (7) because $p^{*}\left(S E_{i j}, \Delta t\right)$ varies remarkably from its background long-term value. In this case, we explicitly account for the $S I$ effects and the occurrence of $T E_{k}$ may strongly affect the tsunami hazard in the short-term assessment

$$
p^{*}\left(S E_{i j}, \Delta t\right) \Rightarrow \text { TotPTH } A_{\text {short-term }}
$$

For example, during an off-shore seismic sequence the probability of strong earthquakes may increase of several orders of magnitude with respect to long-term assessments ([48]). During the seismic sequence 
the probability of all seismic events increases significantly and in the same area also the probability of tsunamigenic earthquakes may increase. As a consequence, $p\left(T E_{k}, \Delta t\right)(\approx 1)$ is not comparable to $p\left(S E_{i j}, \Delta t\right)(\ll 1)$. Similarly, during a volcanic unrest episode the probability of tsunamigenic eruptions (and also earthquakes, and landslides) may increase significantly. Then, "seismic sequence" and/or "volcanic unrest" should be part of the set of possible $T E$ s and their effects should be evaluated to assess the short-term TotPTHA. Those cases pose the issue of the time delay $d t$ passed from the triggering event to the subsequent induced source event. An event is supposed to be a trigger if $d t \ll \Delta t$.

\section{The TotPTH A Application: Naples and Ischia (Italy)}

The scope of the present study is the evaluation of feasibility of the comprehensive TotPTHA methodology in the multi-hazard/multi-risk context for the ByMuR Italian project: Bayesian Multi-Risk Assessment: A case study for natural risks in the city of Naples (http : //bymur.bo.ingv.it/). The $B y M u R$ region was chosen since it may be threatened by several natural hazards and risks of different origin (e.g., volcanic, seismic and tsunamigenic). In the application, the tsunami multi-source assessment is focused on two different types of source (near-field seismic events and mass failures) considering a sufficiently large number of sources. This raises a comment on the other types of tsunamigenic sources. According to the Italian Tsunami Catalogue ([49]), tsunami waves due to volcanic activities occurred in 79, 1631 and 1906. The events are reported with tsunami intensity 2 in Ambraseys-Sieberg Scale (generally, an event of tsunami intensity $\geq 3$ produces run-up of approximately $1 \mathrm{~m}$ while for tsunami intensity equal 2 there is not a clear estimation) and with different reliability. The volcanic sources identified in the region are the Vesuvius and the Campi Flegrei caldera. For a complete evaluation of the hazard, these volcanic sources should be examined in a separate volcanic tsunami hazard assessment to evaluate how the volcanic activity produces tsunami waves in the target area. Once the impact of the tsunamis generated by those sources is evaluated, it would be possible to include them in a multi-source context.

Considering the illustrative purposes of this methodological study, volcanic sources are not included and the selected sets of $S T$ s for the TotPTHA in the region are

- Submarine Seismic Sources (SSSs),

- Submarine Mass Failures (SMFs).

Figure 1 reports the spatial framework of the potentially tsunamigenic sources and the target sites. The target sites for the tsunami hazard assessment are located in the port of the city of Naples and in the island of Ischia.

For the TotPTHA at the target sites the chosen tsunami parameter $Z$ is the run-up and is calculated for each tsunami caused by each $S E$ of each $S T$, similarly to [12] and relative application, [13]. Main characteristics and parameters of the sources are described in the next subsections explaining how they are sampled to construct the statistical datasets. In general, each $S E$ is assumed independent from the others. The $S E$ s may be different in magnitudes and size, even if they belong to the same specific $S T$. Also, each $S E$ is defined by a set of parameters that simplify the geometric shape of the correspondent source. 


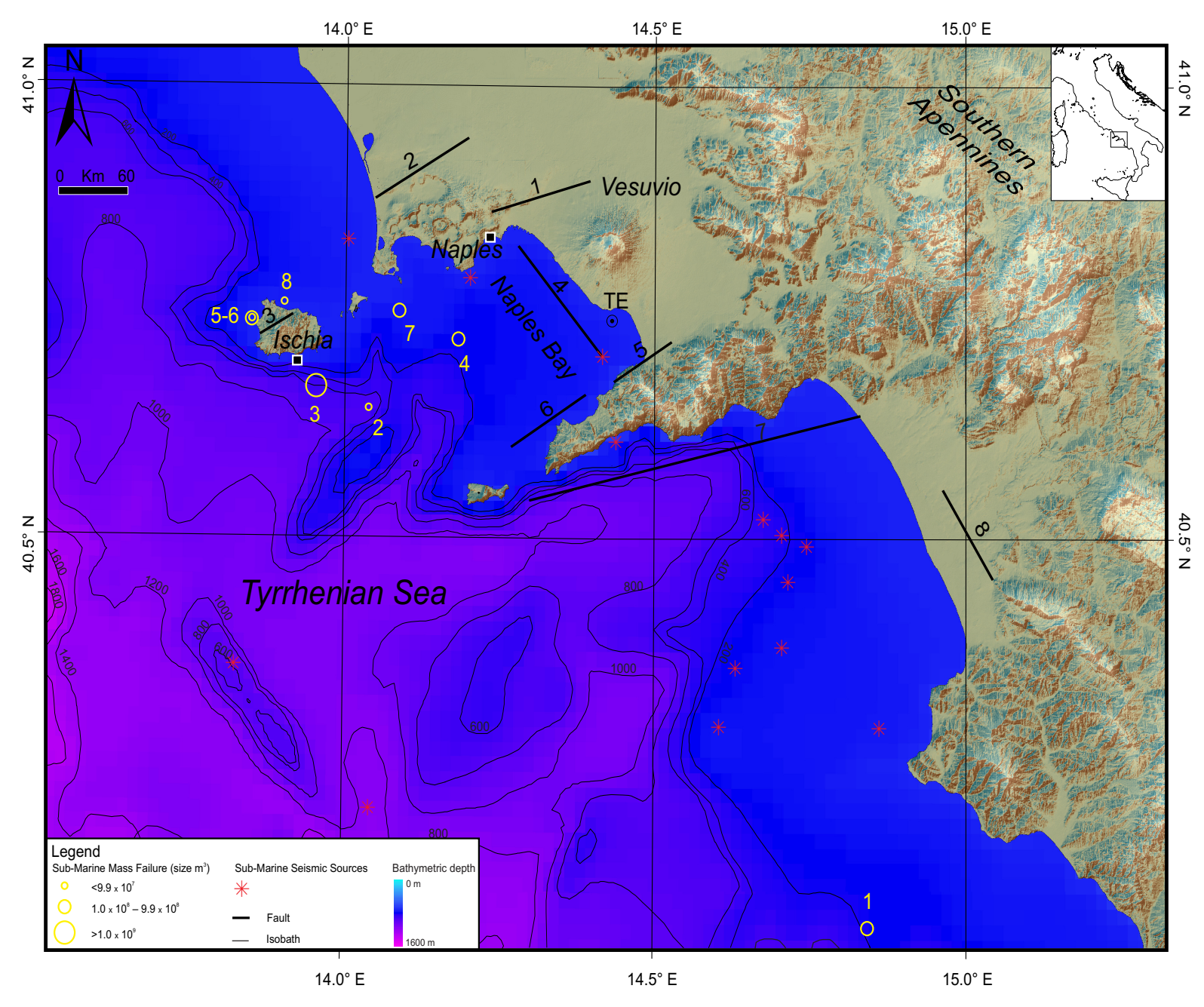

Figure 1. Topography-Bathymetry of the application region: red stars are the submarine seismic sources ( $S S S \mathrm{~s}$ ), the white circles are the past sub-marine mass failures ( $S M F$ s) of different sizes, and the black circle is the triggering event ( $T E$ ) location. The square black boxes correspond to the target sites Ischia and Naples. 
The potentially tsunamigenic $S E$ s of the two $S T$ s determine the tsunami generation phase. The generated initial tsunami waves propagate up to the coast where their impacts are evaluated in terms of the overcoming threshold values $z \in[0.5 \mathrm{~m}, 1 \mathrm{~m}, 2 \mathrm{~m}, \ldots, 10 \mathrm{~m}]$.

Then, we estimate the TotPTHA by Equation (6) computing each PTHA $(i=S S S, S M F)$. For simplicity, in the $P T H A_{i}$ factorization we indicate the $p\left(Z \geq z, S E_{i j} ; \Delta t\right)$ by $P_{i}$. This is the probability that the tsunami parameter $Z$ overcomes the threshold values $z$ in the time interval $\Delta t$ considering $N_{j}$ $\left(j=1, \ldots, N_{i}\right)$ source events $S E \mathrm{~s}$ of $N_{i}(i=S S S, S M F)$ source types $S T$ s. In order to determine the $P T H A_{i}$, the probabilities of occurrence of the $S E$ s of the different $S T$ s are assessed through the following independent factors: spatial probability $P_{i}^{\text {spat }}$, frequency-size probability $P_{i}^{\text {size }}$, and temporal probability $P_{i}^{t e m p}$. Different $S T$ s have different likelihoods and the relative return periods can be longer than the historical records. So that, we express the probability by $P_{i} \times$ year ${ }^{-1}$ for the comparisons.

Finally, we present a discussion on how the TotPTHA changes in the short-term after a possible seismic triggering event in the region.

\subsection{SSSS}

- Spatial Identification. The seismic sources are spatially identified on the active seismic areas and we consider that even small seismicity indicates the presence of major faults ([50]). So that, epicenters are defined considering the recorded seismic events. We extracted the locations of the seismic events in the application region from the Italian Seismological Instrumental and Parametric Database (ISIDe, http : //iside.rm.ingv.it/) available for the period 1983-2009. From the database we selected the latitudes and longitudes of those seismic events occurred with magnitude above the completeness magnitude $\left(M_{w}=2.3\right)$ in the upper ocean crust at depth $(<15 \mathrm{~km})$. In the exemplified study 14 submarine earthquakes occurred in that period and their locations are the $S S S$ s locations (Figure 1).

- Magnitudes and sizes. The moment magnitudes $M_{w}$ associated to each seismic source location are hypothetic in the interval [5.5-7.5] sampled with 0.1 magnitude increment. The introduction of hypothetic magnitudes was necessary because in the ISIDe database the maximum $M_{w}$ recorded in the area was 5.4 and did not caused tsunami. The lower limit was chosen considering the Mediterranean instrumental tsunami observations: a tsunami occurred in the Gulf of Corinth in 11-02-1987 ([51]) after an earthquake of 5.5 magnitude and the concomitant submarine slide. The upper limit was chosen on the basis of the background knowledge of the Tyrrhenian sismo-tectonics indicating that there are no evidence of earthquakes larger than 7.5 in this area in the last two millennia ([52]).

- Geometric Parameters. The geometric parameters of the faults are associated to each $S S S$ location. According to the hypothetic $M_{w}$, the lengths $L$, widths $W$ and slips $S$ of the fault are scaled by Wells and Coppersmith's formulas ([53]). To introduce a certain variability the fault parameters were sampled twice considering different values (randomly chosen) in the relative interval determined by the standard deviation of the fault parameters provided by Wells and Coppersmith. Orientation angles (strike, dip, and rake) are predefined for each location by associating the angles of the nearest submarine fault coherently with the geological/tectonic setting 
of the area considering also inland faults (Figure 1 and Table 1). The choice of faults is based on the current knowledge of Holocenic active faults even in terms of kinematics and geometry in the vicinity of the study area. Indeed, we considered existing catalogs of Holocenic active faults (DISS) and relevant published papers ([54,55]).

- Tsunami Initial Wave and Tsunami Wave Propagation. Two widely accepted assumptions in tsunami modeling are: $(i)$ setting the tsunami initial condition to be equal to the vertical sea floor deformation and (ii) using the linear shallow water theory to describe tsunami propagation in deep waters, where non-linear effects are still negligible. The former is computed by Okada's analytical formulas ([56]) using the source parameters described in the previous section. The latter solves numerically, the conservation of mass and momentum equations for an incompressible fluid expressed by

$$
\begin{gathered}
\frac{\partial \eta}{\partial t}+\frac{\partial M}{\partial x}+\frac{\partial N}{\partial y}=0 \\
\frac{\partial M}{\partial t}+g D \frac{\partial \eta}{\partial x}=0 \\
\frac{\partial N}{\partial t}+g D \frac{\partial \eta}{\partial y}=0
\end{gathered}
$$

where $t$ is the time variable, $x$ and $y$ are the horizontal space coordinates, $g$ is the gravity, $D$ is the total water column $(D=\eta+H$, being $H$ the average water fluid height at the undisturbed level), $\eta$ is the surface water elevation and $M$ and $N$ are the discharged fluxes, defined as the product of the total water column $D$ and the corresponding horizontal components of the velocity $u$ and $v$ directions, respectively in the $x$ and $y$ directions, i.e., $M=D u$ and $N=D v$. Equations (15)-(17) are used to propagate the tsunami waves in waters deeper than the $50 \mathrm{~m}$ isoline, since in shallower water depths the contribution of the non-linear terms cannot be neglected. Similarly, the frictional terms are not included in this formulation, since their importance become relevant as the waves reach the shallower areas close to the coast.

The computational grid is a regular mesh (composed by squared cells having side length $=50 \mathrm{~m}$ ) and it has been set up by matching the GEBCO (http : //www.gebco.net/) 30 arc-second bathymetry and the SRTM (http: //srtm.csi.cgiar.org/) 90 meters topography datasets.

The two assumptions defined above are still a powerful compromise that allows us to represent the most relevant tsunami features (i.e., the main front height and its directivity) with a relatively low computational time cost for each simulation.

- Coastal Effects and Tsunami Impact Evaluation. The final number of initial tsunami waves is $N_{S S S}=588$ according to the described SSSs. The tsunami amplification at the coast is estimated for each tsunami wave using the Green's law based on the energy conservation law. By considering that $(i)$ the wave front is almost parallel to the coast because wave refraction is towards the directions of the down-gradient depth and $(i i)$ the convergence and/or divergence of the rays can be neglected we apply the formula:

$$
H_{1}=\sqrt[4]{\frac{d_{50}}{d_{1}}} H_{50}
$$

where $H_{1,50}$ and $d_{1,50}$ are respectively the tsunami amplitude and the sea depth and the suffixes 50 and 1 refer respectively to the $50 \mathrm{~m}$ and $1 \mathrm{~m}$ depth isolines. Here, run-up estimation is found 
by setting $H_{1}=1 \mathrm{~m}$ as the last wet point, in order to avoid singularity in Equation (17). The use of the Green's law close to the coasts is a common approach for rapid estimation of the maximum tsunami wave height for both probabilistic hazard ([11]) and warning purposes ([57]) and its good agreement with computational results has been demonstrated by [57]. Despite the limit of neglecting the wave reflection that somehow the coast may introduce, an overestimation of the run-ups resulted not relevant. As a consequence, we consider the $H_{1}$ values equivalent to the run-ups $Z$ at the coastal points of the target sites.

3.2. $P_{S S S}$

- Spatial probability $P_{S S S}^{\text {spat }}$. The locations of the submarine epicenters associated to the instrumental records are considered equiprobable and the relative depths of the hypocenters are assigned randomly between 0 and $15 \mathrm{~km}$ of the crust. If necessary, the depths of the hypocenters are conveniently lowered for consistency with the Wells and Coppersmith's formulas.

- Frequency-Size probability $P_{S S S}^{s i z e}$. Large earthquakes are less likely to occur compared to events of smaller magnitude. The SSSs frequency-size relation, known as the Gutenberg-Richter's law ([58]) is computed using a large set of instrumental data in the Tyrrhenian Sea. The events are extracted from the ISIDe database (with location at sea and epicenter depths $\leq 15 \mathrm{~km}$ ). The completeness magnitude is $M_{w}=2.3$ for this database and the resulting $b$-value is equal 1.059. Each 0.1 interval of magnitude in the range [5.5-7.5] identifies a class of magnitude which is weighted using the $S S S$ s frequency-size relation and is associated to each seismic source.

- Temporal probability $P_{S S S}^{\text {time }}$. The annual probability is calculated by the Poisson occurrence that is $1-e^{-\lambda \Delta t}$, where $\lambda$ is the annual rate of occurrence of the potential tsunamigenic $S S S \mathrm{~s}$ and $\Delta t$ is the exposure window. The $\lambda$ is computed in the Tyrrhenian Sea using the ISIDe instrumental data and is 0.01059 .

Table 1. $S S S$ geometric fault parameters by: ${ }^{1}[59],{ }^{2}[60]$.

\begin{tabular}{cccccccc}
\hline Id & Fault Name & Length & Width & Min Depth, Max Depth & Strike & Dip & Rake \\
\hline 1 & Posillipo $^{1}$ & 30.0 & 13.0 & $1.0,9.8$ & 74 & 60 & 270 \\
2 & Neaples $^{1}$ & 30.0 & 13.0 & $1.0,9.8$ & 74 & 60 & 270 \\
3 & Nord Campi Flegrei $^{1}$ & 13.0 & 13.0 & $1.0,9.8$ & 58 & 60 & 270 \\
4 & Casamicciola Terme $^{2}$ & 5.0 & 4.0 & $0.0,3.5$ & 235 & 85 & 270 \\
5 & Castellamare $^{1}$ & 5.0 & 13.0 & $1.0,9.8$ & 58 & 60 & 270 \\
6 & Vico Equense $^{1}$ & 15.0 & 13.0 & $1.0,9.8$ & 58 & 60 & 270 \\
7 & Golfo di Salerno $^{1}$ & 48.0 & 13.0 & $1.0,9.8$ & 78 & 60 & 270 \\
8 & Ponte Barizzo $^{1}$ & 10.0 & 13.0 & $1.0,9.8$ & 150 & 60 & 270 \\
\hline
\end{tabular}


- Spatial Identification. The spatial failure probability of a $S M F$ to occur is identified on the basis of some predominant controlling factors deduced by previous background studies: (1) statistical analysis indicated that the slope angle and the depth of the centre of mass are principal controlling factors ([61]); (2) scars observations indicated that the past mass failures left unstable margins ([62]); (3) earthquake occurrences increase the slide instability ([63]).

In order to compute the spatial probability, the Tyrrhenian Sea was divided in square cells of $1^{\prime}$. The length of the cells is of the same order of magnitude of the major slide indicated by the past events referred in Table 1. Each cell is designed by a weight that is the sum of scores that quantify the informative features. On the basis of points (1), (2) and (3) the proposed scores in the Tyrrhenian Sea are:

(a) 1 in the deep basin or in the coastal zones,

(b) 10 where the average depth of the cell is in the range $1000-1300 \mathrm{~m}$,

(c) 10 where the mean slope of the cell is between $3^{\circ}-5^{\circ}$,

(d) 10 where a factor of safety indicates slide instability in the case of earthquakes,

(e) 20 where the mean slope is $>5^{\circ}$,

as discussed in another application study [13]. The factor of safety $F_{s}$ is computed following [64]:

$$
F_{s}=\frac{\left[1-\left(\gamma / \gamma^{\prime}\right) a_{y}-\left(\gamma / \gamma^{\prime}\right) a_{y} \tan \phi-r_{u} / \cos ^{2} \phi\right]}{\left[1-\left(\gamma / \gamma^{\prime}\right) a_{y}+\left(\gamma / \gamma^{\prime}\right) a_{x} \tan \phi\right]} \tan \rho^{\prime} / \tan \phi
$$

where $\phi$ is the slope angle, $\gamma$ and $\gamma^{\prime}$ are the total and buoyant unit weights of the sediment (typical values are chosen considering the sediment distributions in the Tyrrhenian Sea by [65]), $a_{x}$ and $a_{y}$ are the horizontal and vertical ground acceleration due to the earthquakes expressed in terms of $\%$ of gravity, $r_{u}\left(=u_{e} / \gamma^{\prime} \zeta\right)$ is related to the exceeded pore pressure $u_{e}$ and the sediment thickness $\zeta$, $\tan \rho^{\prime}$ is the coefficient of friction $\left(\rho^{\prime}\right.$ generally ranges between $20^{\circ}$ and $\left.35^{\circ}\right)$.

We simplify by eliminating the terms containing $a_{y}$ and $r_{u}$ because the vertical acceleration may be neglected. Also, the $u_{e}$ excess pore pressure is considered equal nil. This simplification does not take into account the excess pore pressure development for the slides during a seismic event ([66]). The use of the $u_{e}$ value requires a specific knowledge of the accumulated materials at sea that is not available. The case $F_{s}<1$ indicates instability, $F_{s}=1$ is the limit equilibrium and $F_{s}>1$ indicates stability. The horizontal peak ground acceleration $(P G A)$ is set from the best estimate values of the Italian Hazard Map (2004 - http : //zonesismiche.mi.ingv.it/). In each cell we consider the $P G A$ values with the probability of excedence of $16 \%$ and $84 \%$ in 50 years. The correspondent median value is used in Equation (14) with the underlying assumption that such a value represents a reliable indication of the earthquake load that can increase the slide instability and the subsequent probability of mass failure. The highest scores are used for the steep slopes because often they belong to flanks of volcanic structures in the Tyrrhenian Sea. The cell weights range from 1 (the case of cells presenting low mass failure probability to occur where the slope is $<3^{\circ}$, the depths are either $<1000 \mathrm{~m}$ or $>1300 \mathrm{~m}$ and the seismicity is low) up to 40 (the case of cells presenting high mass failure probability to occur where the slope gradient is sharp 
and the depths are between $1000 \mathrm{~m}$ and $1300 \mathrm{~m}$ in an area of high seismicity). The geological records indicating past failures are reckoned by additional weights. The increment corresponds to the number of the past $S M F \mathrm{~s}$ (Table 2). Finally, based on the cell weights we compute by normalization the $S M F$ probability of occurrence, that is predominant: (1) on open continental margins; (2) on the flanks of volcanic islands; and (3) in the areas of high earthquakes occurrence.

- Magnitudes and sizes. The mass failure volumes $V$ are chosen in the interval $\left[5 \times 10^{5}-5 \times 10^{10}\right]$ $\mathrm{m}^{3}$ which was divided in 5 classes of reasonable sizes considering that the tsunami heights and run-ups are related to the volume of the slides ([67]). The classes are chosen on the basis of the past regional events. The lower class is set according to the mass failure of the Stromboli volcano in December 2002 estimated about $5 \times 10^{5} \mathrm{~m}^{3}$ by [68]. The upper class is derived from historical slide sizes mapped using marine geological technique by [69]. A wide set of potential mass failures is produced associating each $S M F$ class to each square cell of $1^{\prime}$ in the Tyrrhenian Sea. For practical reasons, we consider the $S M F$ geometrical parameters in two separate dataset: slides (generally defined as thin, translational failures traveling long distances) and slumps (generally defined as thick, rotational failures occurring with minimal displacement). The slump failures span in the first 4 classes for a total number of events $N_{\text {slump }}=10,000$, whereas the slides span in the full range of the 5 volume classes for an equivalent number of $N_{\text {slide }}=10,000$. The total number of $S M F$ events are $N_{S M F}=20,000$.

- Geometric Parameters. On the basis of the rigid body approximation the length $l$, thickness $s$ and width $w$ deduced by the hypothetic volumes of the mass failures are the basic parameters describing the mass failures. Their regular shape is further simplified as a function of the $S M F$ length, following [70,71]. In other words, it is $s \approx 0.01 l$ and $w \approx 0.25 l$ in the case of submarine slides, and $s \approx 0.1 l$ and $w \approx l$ in the case of submarine slumps. As a consequence, having set the mass failure volumes we simply computed the related parameters $l$.

- Tsunami Initial Wave and Tsunami Wave Propagation. It is calculated by empirical laws that represent approximations at the first order of the initial tsunami wave amplitude $\eta^{\prime}$ ([71]) in the case of slides

$$
\eta^{\prime} \approx 1.7410^{-5} l(1-0.750 \sin \phi)[(l \sin \phi) / d]^{1.75}
$$

and in the case of slump

$$
\eta^{\prime} \approx \operatorname{coef}_{\Delta \Phi} l(\sin \phi)^{0.25}(1+2.06 \sqrt{d / l})^{-1}(l / d)^{1.25}
$$

where $\phi$ is the incline angle, $d$ is the depth of the centre of mass of the submarine slide or slump, $\operatorname{coe}_{\Delta \Phi}$ is the difference between the initial and the final angles of the centre of mass. For specific values we refer to previous application in [13].

- Coastal Effects and Tsunami Impact Evaluation. The initial wave is propagated by the empirical run-up law by [72]

$$
Z=2.381\left(\cot \phi^{\prime}\right)^{\frac{1}{2}} \eta^{\frac{5}{4}} d^{-\frac{1}{4}}
$$

where $\phi^{\prime}$ is the average coastal sea-bottom slope angle in front of the target sites, $\eta\left(=2 \eta^{\prime}\right)$ is the tsunami wave height, and $d$ is the water depth at the source.

This empirical law does not consider: $(i)$ wave propagation effects (refraction, diffraction, etc.) and $(i i)$ nonlinear process (breaking, dispersion, etc.). Here, we produce a first order tsunami 
hazard assessment of mass failures that has to be compared with the tsunami hazard assessment of the seismic type in order to apply the methodology in the region.

\section{4. $P_{S M F}$}

- Spatial probability $P_{S M F}^{\text {spat }}$. The spatial domain is divided in cells where the spatial probability is calculated. The score parameters associated to each cell (see previous paragraph) are converted in spatial probability and normalized to 1 , following [73].

- Frequency-Size probability $P_{S M F}^{s i z e}$. A power law is calculated for the $S M F$ s similarly to the $S S S$ s case by considering known submarine mass failures in the Tyrrhenian Sea ([13,74-76]). The corresponding $b$-value $(=1.3114)$ is computed in order to weight the mass failure classes. Considering the wide range of events the volumes of the $S M F$ s were grouped in 4 (slump cases) or 5 (slide cases) classes weighted by the frequency-size relation.

- Temporal probability $P_{S M F}^{t i m e}$. Also in this case the annual probability is calculated by the Poisson occurrence $1-e^{-\lambda \Delta t}$, where $\lambda$ is the annual rate of occurrence of potential tsunamigenic $S M F \mathrm{~s}$ in the $\Delta t$ exposure window. The $\lambda$ is 0.013 , computed using the available geological background knowledge.

Table 2. $S M F$ parameters by: ${ }^{1}[13],{ }^{2}[74],{ }^{3}[75],{ }^{4}[76]$.

\begin{tabular}{|c|c|c|c|}
\hline Id & $S M F$ Name & Size $m^{3}$ & Time, Years Before Present \\
\hline 1 & Capo Licosa ${ }^{1}$ & $3.2 \times 10^{8}$ & 14,000 \\
\hline 2 & Baia Napoli (Gaia Bank) ${ }^{2}$ & $3.8 \times 10^{6}$ & $15,000-6000$ \\
\hline 3 & Baia Napoli (Dohrn Canion) ${ }^{2}$ & $100 \times 10^{6}$ & $15,000-6000$ \\
\hline 4 & Baia Napoli (Miseno Bank) $^{2}$ & $200 \times 10^{6}$ & $15,000-6000$ \\
\hline 5 & Ischia Nord ${ }^{3}$ & $15-20 \times 10^{6}$ & $3000-2400$ \\
\hline 6 & Ischia Sud ${ }^{3}$ & $1.5 \times 10^{9}$ & 23,000 \\
\hline 7 & Ischia West ${ }^{3,4}$ & $80-150 \times 10^{6}$ & 5500 \\
\hline 8 & Ischia West ${ }^{3,4}$ & $1 \times 10^{6}$ & 5500 \\
\hline
\end{tabular}

\section{The TotPTH $A_{\text {long-term }}$}

Finally, the $P T H A_{i}$ is assessed by each factor $P_{i}$ through Equation (7)

$$
p\left(Z \geq z, S E_{i j} ; \Delta t\right)=\mathcal{H}(Z \geq z) \cdot\left(P_{i}^{\text {spat }} \cdot P_{i}^{\text {size }} \cdot P_{i}^{\text {time }}\right)
$$

where $\mathcal{H}(Z \geq z)$ is the Heaviside step function (that is 1 if the run-ups $Z$ are larger than the threshold levels of $z \in[0.5 \mathrm{~m}, 1 \mathrm{~m}, 2 \mathrm{~m}, \ldots, 10 \mathrm{~m}]$ and 0 in the other cases) and the factors $P_{i}$ represent the non-interactive source probabilities.

If $P_{i}$ defines the probability of occurrence of at least one tsunami event and $\left(1-P_{i}\right)$ the generic probability that no tsunami occurs, then the final probability $P_{\text {long-term }}$ is

$$
P_{\text {long-term }}=1-\left[\left(1-P_{S S S}\right)\left(1-P_{S M F}\right)\right]
$$


that combines both factors $P_{i}(i=S S S$ and $S M F)$. The TotPTH $A_{\text {long-term }}$ is shown in Figure 2 and the relative probabilities $\times$ year ${ }^{-} 1$ of $z \geq 0.5 \mathrm{~m}$ and $z \geq 1 \mathrm{~m}$ at the target sites Naples and Ischia are listed in Table 3. Equation (23) takes into account also tsunami events produced by $S M F$ s triggered by $S S S$ s assuming that the sources are independent.
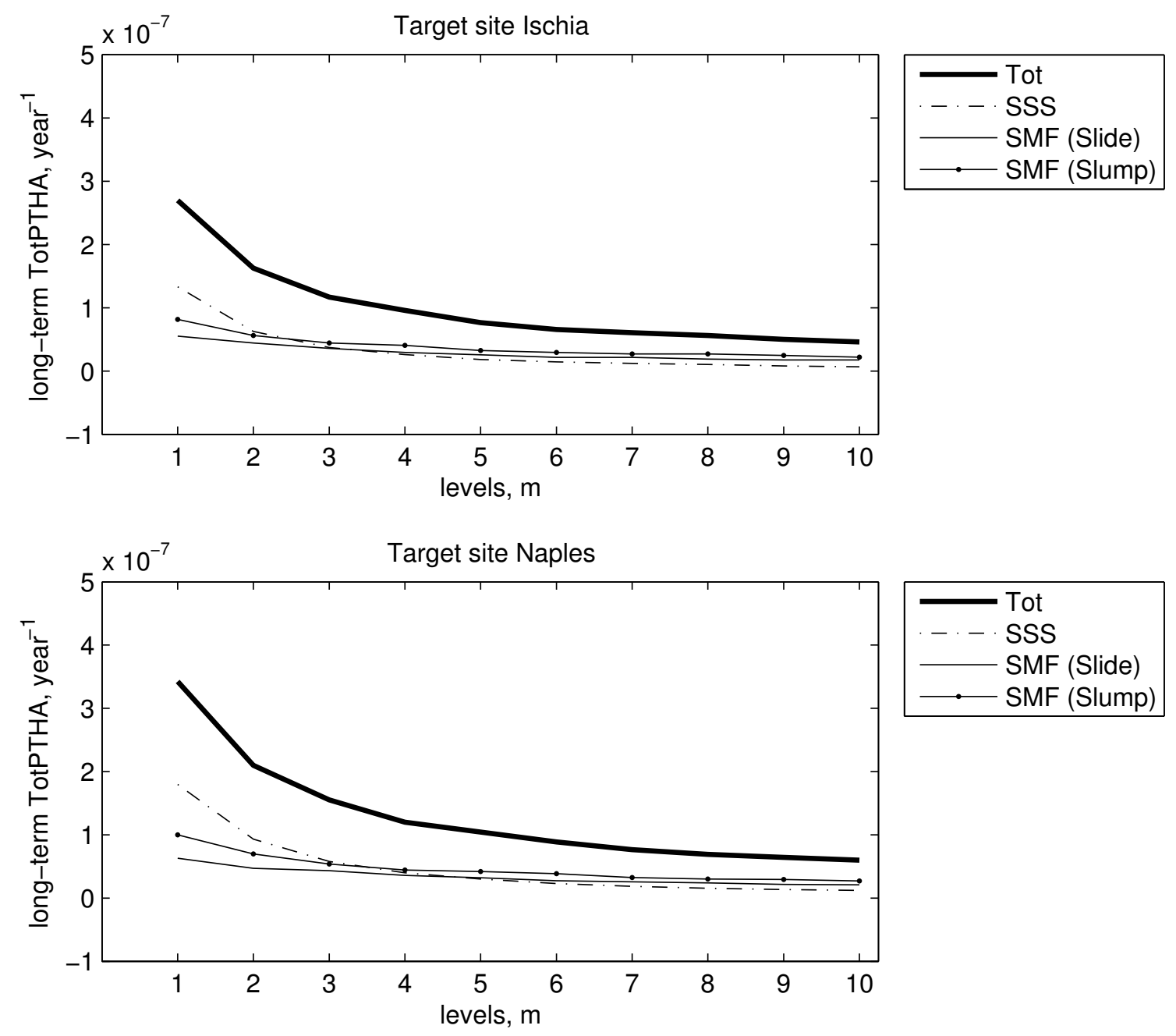

Figure 2. TotPTH $A_{\text {long-term }}$ at the target sites. The TotPTHA takes into account the PTHA $A_{i}$ where $i$ indicates $S S S \mathrm{~s}, S M F \mathrm{~s}$ (Slides and Slumps).

Table 3. TotPT H $A_{\text {long-term }} \times$ year ${ }^{-1}$ to overcome $0.5 \mathrm{~m}$ and $1 \mathrm{~m}$ run-ups at the island of $I$ schia and the port of the city of Naples.

\begin{tabular}{lcccc}
\hline & Ischia: $\mathbf{0 . 5} \boldsymbol{m}$ & $\mathbf{1} \boldsymbol{m}$ & Naples: $\mathbf{0 . 5} \boldsymbol{~}$ & $\mathbf{1 ~} \mathbf{m}$ \\
\hline SSS & $1.353 \times 10^{-6}$ & $3.915 \times 10^{-7}$ & $2.400 \times 10^{-6}$ & $1.230 \times 10^{-6}$ \\
SMF (slide) & $1.121 \times 10^{-7}$ & $8.222 \times 10^{-8}$ & $1.342 \times 10^{-7}$ & $9.344 \times 10^{-8}$ \\
SMF (slump) & $1.625 \times 10^{-7}$ & $1.274 \times 10^{-7}$ & $1.837 \times 10^{-7}$ & $1.422 \times 10^{-7}$ \\
TotPT H A $A_{\text {long-term }}$ & $1.627 \times 10^{-6}$ & $6.011 \times 10^{-7}$ & $2.718 \times 10^{-6}$ & $1.466 \times 10^{-6}$ \\
\hline
\end{tabular}


This assumption is realistic by considering the time lag between a $S S S$ event and the triggered $S M F$ event. In other words the two events are well separated in time: the triggering event occurs in a time duration of an order of seconds, the triggered event may occur after minutes or hours.

\section{The TotPTH $A_{\text {short-term }}$ in the Case of the TEs}

The TotPTHA can be modified (and eventually increased) by the occurrence of an earthquake. Now we compute the TotPTH $A_{\text {short-term }}$ through time at both target sites in case a triggering event $T E$ occurs, that is one submarine earthquake of magnitude $M_{T E}$ at time $t_{T E}$. To model the influence of $T E$ on the other potential seismic sources we apply the epidemic-type aftershock sequence $(E T A S)$ model ([77-80]) to the seismicity of $S S S \mathrm{~s}$ in the region.

The fundamental concept of the ETAS model is that each earthquake can trigger subsequent events $([50,81,82])$ and seismicity can be generated by the aftershocks. Also the model assumes that the aftershock activity cannot always be predicted by a single modified Omori function but each aftershock is able to perturb the earthquake rate and generate its own Omori aftershock decay dependent on the magnitude ([83,84]). In general, the temporal seismicity rate $\lambda^{\prime}$ of a specific area is the sum of two terms ([85]:

$$
\lambda^{\prime}=\lambda_{b}+\lambda_{E T A S}
$$

the first term $\left(\lambda_{b}\right)$ is the rate of background that is not triggered by the previous earthquakes in the catalogue and the second one $\left(\lambda_{E T A S}\right)$ is the rate of the triggered event that is associated to the stress perturbations generated by the previous earthquakes in the catalogue. In this practical application, the background seismicity rate is considered equal to the one computed in the long-term analysis. According to the ETAS model assumptions the total space-time conditional intensity is the probability of an earthquake occurring in the infinitesimal space-time volume conditioned to the past history [85]. For simplicity, we consider only one main shock $T E$ and we neglect the sequence of aftershocks. It is worth to note that this results in an underestimation of the effect of a large $T E$ on the final tsunami hazard. The $\lambda_{E T A S}$ represents the contribution to the annual seismicity rate in the region in each location and it is expressed according to [85] by

$$
\lambda_{E T A S}=\frac{K}{\left(t_{o b}-t_{T E}+c\right)^{\Pi}} e^{\alpha\left(M_{T E}-M_{c}\right)} \frac{\frac{(q-1)}{\pi} G^{2(q-1)}}{\left(r_{i}^{2}+G^{2}\right)^{q}} \beta e^{-\beta\left(M_{w}-M_{c}\right)}
$$

where $t_{T E}(=0)$ is the time when the $T E$ of moment magnitude $M_{T E}=5.4$ occurs, $t_{o b}$ is the observation time after the $T E, M_{c}$ is the completeness magnitude of the instrumental catalogue, $r_{i}$ is the distance between the potential tsunamigenic $S S S$ s and the epicenter of the $T E$ and $\beta=b \ln (10)$ is the parameter of the Gutenberg-Richter's law $(b=1.059)$. The values of the other parameters in Equation $(25)$ are: $K=0.011, c=0.00004, \Pi=1.16, \alpha=1.3, G=1.1$ and $q=1.5$ according to [85].

As stated in Equation (13), the TotPTH $A_{\text {short-term }}$ is performed again through Equation (6) where the source phase probability in Equation (7) is assessed accounting for $S I$ through Equation (10)

$$
p^{*}\left(S E_{i j}, \Delta t\right)=p\left(S E_{i j}, \Delta t\right)+1-e^{-\lambda_{E T A S} \Delta t}
$$

where the first term is assessed by Equation (22) and $\lambda_{E T A S}$ through Equation (25). We consider an exposure time window $\Delta t$ of 7 days. The results are shown in Figure 3 at the target sites. 
Immediately after the $T E$ event (after 1 day, 2 days and 7 days) the probabilities increase. For example in the case of $0.5 \mathrm{~m}$ and $1 \mathrm{~m}$ run-up the TotPTHA $A_{\text {short-term }}$ is three order of magnitudes higher than the TotPTH $A_{\text {long-term }}$ (Table 4). On the other hand, 30 days after the TE there are no more significant effects on the TotPTHA $A_{\text {short-term }}$ and the probability values are back to the TotPTH $A_{\text {long-term }}$ assessment.
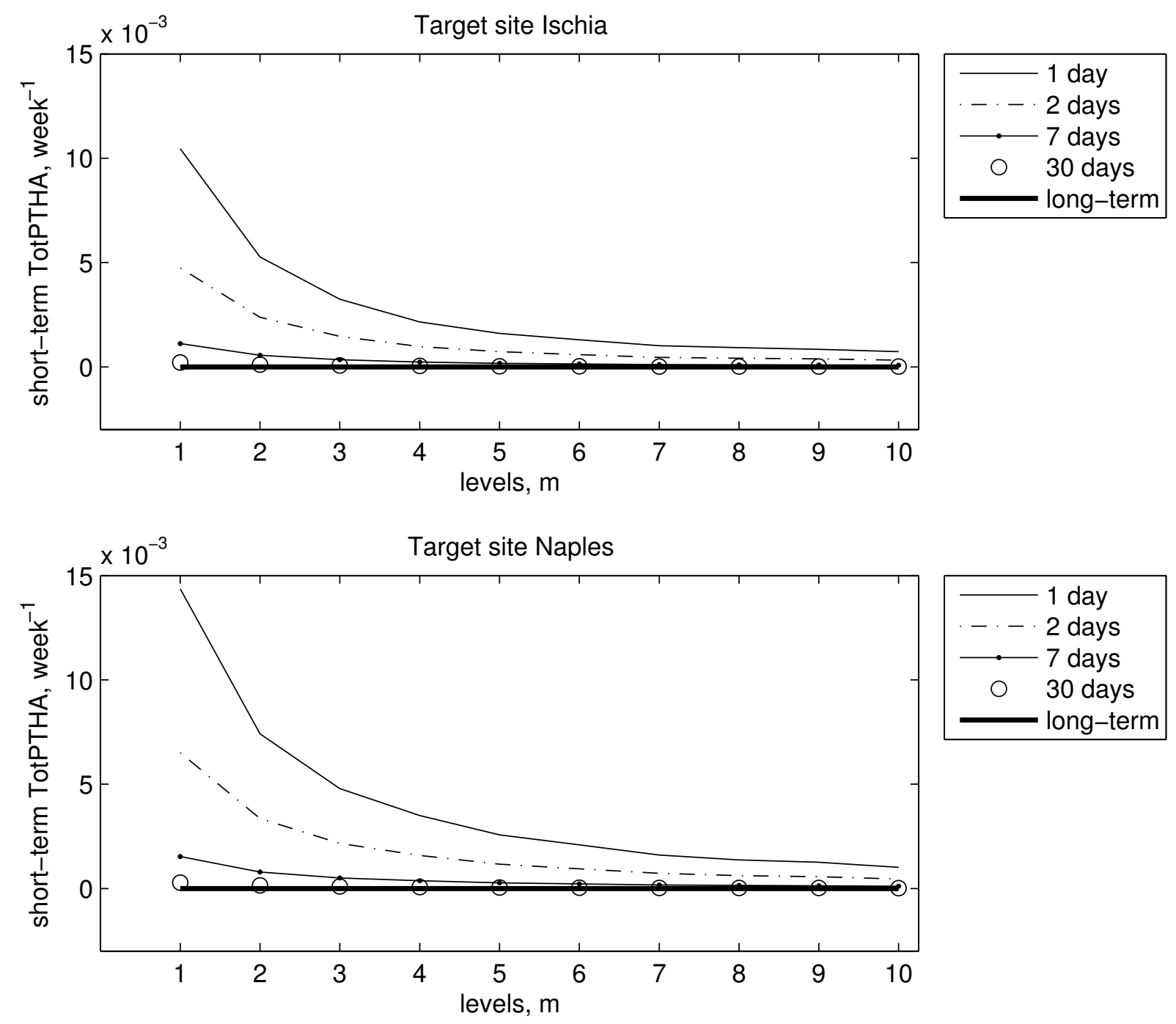

Figure 3. Probability at the target sites, applying the ETAS model after the triggering event $T E$, a submarine earthquake of magnitute $M_{w}=6.8$.

In the case of Equation (26) the independence between the $T E$ and the $S S S$ is assumed. Also, the choice of $M_{T E}=5.4$ makes the $T E$ an external event to the dataset used to evaluate the $p\left(S E_{i j}, \Delta t\right)$. 
Table 4. TotPTH $A_{\text {short-term }}$ to overcome $0.5 \mathrm{~m}$ and $1 \mathrm{~m}$ run-ups after 1 day, 2 days, 7 days and 30 days due to the $T E$ considering the exposure time window of 7 days at the island of Ischia and the port of the city of Naples.

\begin{tabular}{lcccc}
\hline TotPT H A $\boldsymbol{A}_{\text {short-term }}$ & Ischia: $\mathbf{0 . 5} \boldsymbol{m}$ & $\mathbf{1} \boldsymbol{m}$ & Naples: $\mathbf{0 . 5} \boldsymbol{m}$ & $\mathbf{1} \boldsymbol{m}$ \\
\hline Day 1 & $1.624 \times 10^{-2}$ & $5.786 \times 10^{-3}$ & $7.333 \times 10^{-2}$ & $2.412 \times 10^{-2}$ \\
Day 2 & $7.363 \times 10^{-3}$ & $2.615 \times 10^{-3}$ & $3.378 \times 10^{-2}$ & $1.096 \times 10^{-2}$ \\
Day 7 & $1.737 \times 10^{-3}$ & $6.158 \times 10^{-4}$ & $8.052 \times 10^{-3}$ & $2.588 \times 10^{-3}$ \\
Day 30 & $1.155 \times 10^{-3}$ & $8.556 \times 10^{-4}$ & $1.496 \times 10^{-3}$ & $4.799 \times 10^{-4}$ \\
\hline
\end{tabular}

\section{Discussion, Limitations and Further Work}

In this paper we describe a general methodology for a comprehensive and total probabilistic tsunami hazard assessment (TotPTHA) that coherently merges the probabilistic hazards computed on the basis of a number of tsunamigenic events due to different source types. In practice, we evaluate the methodology and its potential by selecting two target sites in Italy as illustrative cases, the city of Naples and the Island of Ischia. In order to show the applicability of the TotPTHA methodology many important simplifications are required and their limitations in the application are discussed. However, we would like to remark that this case study means to be illustrative of the proposed methodology for the TotPTHA without meaning to be complete for the final hazard assessment.

On the basis of historical information from the Italian Tsunami Catalogue ([49]) three definite (maximum reliability) tsunami events occurred in Naples (in 1631, 1805, 1906) with tsunami intensity 2 in Ambraseys-Sieberg Scale. They were associated to earthquakes or volcanic activity. There is no explicit reference to tsunami caused by submarine mass failures in the historical period. On the other hand, extensive long-range side scan sonar survey ([86]) showed that a catastrophic collapse occurred in pre-historical time (3000-2400 years before present) at the Ischia Island driven by the volcano-tectonic uplift of Mt. Epomeo. This major collapse was likely followed by less catastrophic terrestrial and submarine failures. Simulation of such event showed that giant waves could impact on the Tyrrhenian coasts ([87]).

Firstly, to compute a fully comprehensive TotPTHA in the region, multiple tsunamigenic sources must be taken into account. In fact, the estimation of the PTHA considering only a single type of source (the seismic one) may generate biases and underestimations. In the application at the two target sites we evaluate the tsunami hazard produced by the submarine seismic events and the submarine mass failures. Other sources, related to the volcanic sources like the pyroclastic flows and the caldera activities should be considered. Even if we recognize their importance in the area in terms of $S T_{\text {repres }}$ and the possible implications on the TotPTHA they are not explored in this application. Major information are missing on the tsunami waves associated to volcanic events in the area. Therefore, in the present application we do not include the volcanic sources in order to avoid additional biases.

Secondly, the analysis is focused on the near sources, both $S S S \mathrm{~s}$ and $S M F \mathrm{~s}$, and the choices of the source datasets pose the problem of the $S E_{\text {repres }}$. Source information on seismic faults decrease with the distance from the Gulf of Naples and are often unknown/incomplete. In the past two millennia 
there is no reported seismic event far in the Tyrrhenian Sea that produced tsunami waves at the target sites. The use of the instrumental database is an additional way to identify the active faults offshore. In the application case, the database $I S I D e$ indicates a region of interest wider than the existing faults but covers a very short time period. The missing information in the database have to be compensated by the general background knowledge of the tectonic/geological setting. In order to overcome the afore-mentioned limitations of the databases/catalogues we should consider alternative strategies aimed to enlarge the number of events considered in the dataset. A solution could be the introduction of a gridded domain to systematically explore the potentially tsunamigenic $S S S$ s in unknown locations. In this way, the source dataset is expanded by identifying the grid centers and/or corners as locations of the epicenters in the binned domain. Also, we can use a larger set of faults by adding more randomness in the other parameters. Other relevant far sources may be identified in the Southern Tyrrhenian Sea and the Northern African coasts to complete the dataset of the $S S S \mathrm{~s}$. The limitations posed by the completeness and the length of the databases/catalogues indicate the need of further studies in the area of the application.

Beside the problem of a missing complete catalogue also for the $S M F$ case, the description of the mass failures and the computation of the relative run-ups undergo to simplifications and approximations that do not take into account distance, orientation and bathymetry between sources and target sites [88]. A slide modeling would improve the determination of the run-ups by using more realistic slope and water depth in the shallowest part of the domain. As a consequence, uncertainties related to the $Z$ parameter would be reduced.

Despite the discussed limitations, important achievements have been obtained by applying the TotPTHA methodology for the multi-source case. In both target sites the multiple-source effect on the TotPTHA is the increasing of the hazard in the long-term analysis compared to the hazard posed by a single type of source. In fact, the TotPTHA in the long-term case remarkably increases after considering submarine mass failures along with the potential submarine seismic events. Even in not definitive analysis (like the present application), once the multi-hazards are formally assessed and the relative importances of the $P T H A_{S S S}$ and the $P T H A_{S M F}$ terms are computed in the TotPTH $A_{\text {long-term }}$ then it is possible to consider the source interactions. In the case of a triggering seismic event there are relevant changes in the short-term TotPTHA.

\section{Conclusions}

The scope of this study is to present a methodology for the total probabilistic tsunami hazard assessment (TotPTHA) produced by multiple tsunamigenic sources in the framework of the ByMuR Italian project: Bayesian Multi-Risk Assessment: A case study for natural risks in the city of Naples (http://bymur.bo.ingv.it/).

In an exemplified application we illustrate the methodology at two target sites (the port of Naples and the island of Ischia) focusing the analysis on: (1) the multi-hazard approach and (2) the long-and short-term hazard assessments.

1. We demonstrate the applicability of the proposed comprehensive TotPTHA to treat the interactions among different tsunami hazards. Indeed, in the selected region the tsunami waves 
may be generated by different types of sources (near submarine seismic events $S S S$ s and submarine mass failures $S M F$ s) at the target sites. We computed the TotPTHA $A_{\text {long-term }} \times$ year $^{-1}$ and we show that the hazard curve increases when non-seismic $S T$ s are included in the analysis and formally considered together rather than separately;

2. We compute the TotPTH $A_{\text {short-term }}$ by considering a submarine earthquake as triggering event $T E$. In other words, a seismic event (external to the seismic dataset used to produce the hazard) acts as a perturbation of the regional seismicity. We show that the TotPTH $A_{\text {short-term }}$ changes remarkably compared to the TotPTH $A_{\text {long-term }}$ and increases for a limited time window (few days).

In order to perform a more realistic and complete TotPTHA for the selected target sites, further improvements are needed by considering, for example, the tsunamigenic volcanic sources and the far field seismic sources in the Southern Tyrrhenian Sea and Northern Africa coasts. However, we have illustrated how the proposed TotPTHA methodology can be applied in order to potentially consider any kind of tsunami sources and their interactions for both short- and long-term hazard purposes.

\section{Acknowledgments}

We thank the Editor Valentin Heller and we are particularly grateful to three anonymous reviewers/referees for the constructive suggestions and comments that strongly improved the paper. This study was supported by the Italian project ByMuR http://bymur.bo.ingv.it.

\section{Author Contributions}

Conceived and designed the methodology: AG, LS, JS. Identified and provided the seismic sources: SP. Performed the numerical simulations: RT. Wrote the paper: AG. Commented on and improved the review: AG, RT, LS, SP, JS.

\section{Abbreviations/Nomenclature}

$\alpha$ : parameter to determine the triggering capability depending on magnitude

$a_{x}$ : horizontal ground acceleration

$a_{y}$ : vertical ground acceleration

$\beta$ : parameter of the the Gutenberg - Rchter's law

$b$ : coefficient of the Gutenberg - Rchter's law

$c$ : parameter of the modified Omori Law

$d$ : depth

$D$ : height of the total water column

$\phi$ : slope and/or incline angle

$\phi^{\prime}$ : coastal sea-bottom slope angle

$F_{s}$ : factor of safety

$\gamma$ : total unit weight of the sediment

$\gamma^{\prime}$ : buoyant unit weight of the sediment

$g$ : gravity 
$G$ : parameter characterizing the spatial probability density function of the triggered event

$H$ : average water fluid height

$K$ : parameter of the modified Omori Law

$\lambda$ : annual rate of occurrence

$\lambda^{\prime}$ : rate of background

$\lambda_{E T A S}:$ rate of the triggering event

$l$ : slide and/or slump length

$L$ : fault length

$M$ : discharged water fluxes in the eastward direction

$M_{1,2,3}$ : number of generated tsunami events

$M_{c}$ : magnitude threshold for Italian territory in ETAS model

$M_{T E}$ : magnitude of the triggering event

$M_{w}$ : Moment Magnitude

$\eta$ : tsunami surface elevation

$\eta^{\prime}$ : tsunami wave amplitude

$N$ : discharged water fluxes in the northward direction

$N_{\text {slide }}$ : number of slides

$N_{\text {slump }}$ : number of slumps

$N_{S M F}$ : number of Submarine Mass Failures

$N_{S S S}$ : number of Submarine Seismic Sources

$N_{T E}$ : number of Triggering Events

$N_{\text {TOT }}$ : total number of events

$\Pi$ : parameter of the modified Omori Law

$P_{i}$ : probability

PSHA : Probabilistic Seismic Hazard Assessment

PTHA : Probabilistic Tsunami Hazard Assessment

PVHA : Probabilistic Volcanic Hazard Assessment

$q$ : parameter characterizing the spatial probability density function

$\rho^{\prime}$ : coefficient of friction

$r_{i}$ : distance between the potential tsunamigenic seismic sources and the epicenter of the triggering event

$r_{u}$ : parameter of the exceeded pore pressure

$s$ : slide and/or slump thickness

$S$ : slip fault

SI : Source Interaction

$S E$ : Source Event

$S E_{\text {repres }}$ : Source Event representativeness

SMF: Submarine Mass Failure

SSS: Submarine Seismic Source

ST : Source Type

$S T_{\text {repres }}:$ Source Type representativeness

$t:$ time 
$t_{o b}$ : observation time after the triggering event

$t_{T E}$ : time of the triggering event

$\Delta t$ : exposure time window

$T_{1,2,3}$ : number of total tsunamis

TE : Triggering Event

TotPTHA : Total Probabilistic Tsunami Hazard Assessment

$u$ : $x$-component of the horizontal velocity

$u_{e}$ : exceeded pore pressure

$v: y$-component of the horizontal velocity

$V$ : slide and/or slump volume

$w$ : slide and/or slump width

$W$ : fault width

$\zeta$ : sediment thickness

$z$ : thresholds of the level run-ups

$Z$ : run-ups

\section{Conflicts of Interest}

The authors declare no conflict of interest.

\section{References}

1. Liu, Y.; Santos, A.; Wang, S.M.; Shi, Y.; Liu, H.; Yuen, D.A. Tsunami hazards along Chinese Coast from potential earthquakes in South China Sea. Phys. Earth Plan. Int. 2007, 163, 233-244.

2. Power, W.; Downes, G.; Stirling, M. Estimation of tsunami hazard in New Zealand due to South American earthquakes. Pure Appl. Geophys. 2007, 164, 547-564.

3. Rikitake, B.T.; Aida, I. Tsunami hazard probability in Japan. Bull. Seismol. Soc. Am. 1988, 78, 1268-1278.

4. Tonini, R.; Pagnoni, G.; Tinti, S. Modeling the 2004 Sumatra tsunami at Seychelles Islands: site-effect analysis and comparison with observations. Nat. Haz. 2014, 70, 1507-1525.

5. Burbidge, D.; Cummins, P.R.; Mleczko, R.; Thio, H.K. A probabilistic tsunami hazard assessment for Western Australia. Pure Appl. Geophys. 2008, 165, 2059-2088.

6. Burroughs, S.M.; Tebbens, S.F. Power-law scaling and probabilistic forecasting of tsunami runup heights. Pure Appl. Geophys. 2005, 162, 331-342.

7. Tinti, S.; Armigliato, A.; Tonini, R.; Maramai, A.; Graziani, L. Assessing the hazard related to tsunamis of tectonic origin: A hybrid statistical-deterministic method applied to Southern Italy coasts. ISET J. Earthq. Tech. 2005, 42, 189-201.

8. Orfanogiannaki, K.; Papadopoulos, G. Conditional probability approach of the assessment of tsunami potential: Application in three tsunamigenic regions of the Pacific Ocean. Pure Appl. Geophys. 2007, 164, 593-603.

9. Geist, E.L.; Parsons, T. Probabilistic Analysis of Tsunami Hazards. Nat. Haz. 2006, 37, 277-314. 
10. Gonzalez, F.L.; Geist, E.L.; Jaffe, B.; Kanoglu, U.; Mofjeld, H.; Synolakis, C.E.; Titov, E.E.; Arcas, D.; Bellomo, D.; Carlton, D.; et al. Probabilistic Tsunami Hazard Assessment at Seaside, Oregon, for near- and far-field seismic sources. J. Geophys. Res. 2009, 114, 1-19.

11. Sörensen, M.B.; Spada, M.; Babeyko, A.; Wiemer, S.; Grünthal, G. Probabilistic tsunami hazard in the Mediterranean Sea. Geophys. Res. Lett. 2012, 117, B01305.

12. Grezio, A.; Marzocchi, W.; Sandri, L.; Gasparini, P. A Bayesian procedure for Probabilistic Tsunami Hazard Assessment. Nat. Haz. 2010, 53, 159-174.

13. Grezio, A.; Sandri, L.; Marzocchi, W.; Argnani, A.; Gasparini, P. Probabilistic Tsunami Hazard Assessment for Messina Strait Area (Sicily-Italy). Nat. Haz. 2012, 64, 329-358.

14. Tatsumi, D.; Calder, C.A.; Tomita, T. Bayesian near-field tsunami forecasting with uncertainty estimates. J. Geophys. Res. Oceans 2014, 119, 2201-2211.

15. Annaka, T.; Satake, K.; Sakakiyama, T.; Yanagisawa, K.; Shuto, N. Logic-tree approach for Probabilistic Tsunami Hazard Analysis and its applications to the Japanese Coasts. Pure Appl. Geophys. 2007, 592, 164-577.

16. Heidarzaed, M.; Kijko, A. A Probabilistic Tsunami Hazard Assessment for the Makran subduction zone at the Northwestern Indian Ocean. Nat. Haz. 2011, 56, 577-593.

17. Grilli, S.T.; Taylor, S.O.; Baxter, C. D.P.; Maretzki, S. A probabilistic approach for determining submarine landslides tsunami hazard along the upper East Coast of the United States. Mar. Geol. 2009, 264, 74-97.

18. ten Brink, U.S.; Geist, E.L.; Andrews, B.D. Size distribution of submarine landslides and its implication to tsunami hazard in Puerto Rico. Geophys. Res. Lett. 2006, 33, L11307.

19. Gisler, G.; Weaver, R.; Mader, C.; Gittings, M. Two-dimensional simulations of explosive eruptions of Kick'emjenny and other submarine volcanoes. Sci. Tsunami Haz. 2006, 25, 34-41.

20. Heinrich, P.; Mangeney, A.; Guibourg, S.; Roche, R. Simulation of water waves generated by a potential debris avalanche in Montserrat, Lesser Antilles. Geophys. Res. Lett. 1998, 25, 3697-3700.

21. Lövholt, F.; Pedersen, G.; Gisler, G. Oceanic propagation of a potential tsunami from the La Palma Island. J. Geophys. Res. 2008, 113, 9-26.

22. Mader, C. Modeling the La Palma Landslide. Sci. Tsunami Haz. 2008, 19, 150-170.

23. Strunz, G.; Post, J.; Zosseder, K.; Wegscheider, S.; Muck, M.; Riedlinger, T.; Mehl, H.; Dech, S.; Birkmann, J.; Gebert, N.; et al. Tsunami risk assessment in Indonesia. Nat. Haz. Earth Syst. Sci. 2004, 11, 67-82.

24. Ward, S.N.; Day, S. Cumbre Vieja volcano ï ; Potential collapse and tsunami at La Palma, Canary Islands. Geophys. Res. Lett. 2003a, 28, 3397-3400.

25. Poisson, B.; Pedreros, R. Numerical modelling of historical landslide-generated tsunamis in the French Lesser Antilles. Nat. Haz. Earth Syst. Sci. 2010, 10, 1281-1292.

26. Choi, B.H.; Pelinovsky, E.S.; Kim, K.O.; Lee, J.S. Simulation of the trans-oceanic tsunami propagation due to the 1883 Krakatau volcanic eruption. Nat. Haz. Earth Syst. Sci. 2003, 3, 321-332.

27. Ward, S.N.; Day, S. Ritter Island volcano: Lateral collapse and tsunami of 1888. Geophys. J. Int. 2003b, 154, 891-902. 
28. Braathen, A.; Blikra, L.H.; Berg, S.; Karlsen, F. Rock-slope failures in Norway; type, geometry and hazard. Nor. J. Geol. 2004, 84, 67-88.

29. Fritz, H.M.; Hager, W.H.; Minor, H.E. Lituya bay case: Rockslide impact and wave run-up. Sci. Tsunami Haz. 2001, 19, 3-22.

30. Fritz, H.; Mohammed, F.; Yoo, J. Lituya Bay landslide impact generated mega-tsunami 50th anniversary. Pure Appl. Geophys. 2009, 175, 166-153.

31. Harbitz, C.; Pedersen, G.; Gjevik, B. Numerical simulations of large water waves due to landslides. J. Hydr. Eng. 1993, 119, 1325-1342.

32. Miller, D. Giant waves in Lituya Bay, Alaska. U.S. Geol. Surv. 1960, 354-C, 51-84.

33. Bondevik, S.; Lövholt, F.; Harbitz, C.; Mangerud, J.; Dawson, A.; Svendsen, J. The storegga slide tsunami comparing field observations with numerical simulations. Ormen Lange Spec. Issue Marine Petrol. Geol. 2005, 208, 22-195.

34. Fine, I.V.; Rabinovich, A.B.; Bornhold, B.D.; Thompson, R.E.; Kulikov, E.A. The Grand Banks landslide-generated tsunami of November 18, 1929: Preliminary analysis and numerical modelling. Mar. Geol. 2005, 215, 45-57.

35. Haflidason, H.; Sejrup, H.P.; Nygard, A.; Mienert, J.; Bryn, P.; Reidar, L.; Forsberg, C.F.; Berg, K.; Masson, D. The Storegga Slide: Architecture, geometry and slide development. Mar. Geol. 2004, 213, 201-234.

36. Tappin, D.; Watts, P.; Grilli, S. The Papua New Guinea tsunami of 17 July 1998: Anatomy of a catastrophic event. Nat. Haz. Earth Syst. Sci. 2008, 8, 243-266.

37. Leonard, L.J.; Rogers, G.C.; Mazzotti, S. Tsunami hazard assessment of Canada. Nat. Haz. 2014, 70, 237-274.

38. Chesley, S.; Ward, S. A quantitative assessment of the human and economic hazard from impact-generated tsunami. Nat. Haz. 2006, 38, 355-374.

39. Marzocchi, W.; Garcia-Aristizabal, A.; Gasparini, P.; Masellone, M.L.; di Ruocco, A.; Novelli, P. Basic principles of multi-risk assessment: A case study in Italy. Nat. Haz. 2012, 62, 551-573.

40. Selva, J. Long-term risk assessment: Statistical treatment of interaction among risks. Nat. Haz. 2013, 67, 701-722.

41. Grünthal, G.; Thieken, A.H.; Schwarz, J.; Radtke, K.S.; Smolka, A.; Merz, B. Comparison Risk Assessments for the city of Cologne - Storm, Floods, Earthquakes. Nat. Haz. 2006, 30, 21-44.

42. Gusiakov, V. Tsunami History: Recorded. In The Sea; Bernard, E.N., Robinson, A.R., Eds.; Harvard University Press: Boston, MA, USA, 2009; p. 15.

43. McGuire, R. Probabilistic seismic hazard analysis: Early history. Earthq. Eng. Struct. Dyn. 2008, 37, 329-338.

44. Marzocchi, W.; Sandri, L.; Selva, J. BET_VH: A probabilistic tool for long term volcanic hazard assessment. Bull. Volcan. 2010, 72, 705-716.

45. Cornell, C.A. Engineering seismic risk analysis. Bull. Seismol. Soc. Am. 1968, 58, 1583-1606.

46. Geist, E.L.; Parson, T. Distribution of tsunami inter-event times. Geophys. Res. Lett. 2008), 35, L02612. 
47. Titov, V.; Moore, C.; Greenslade, D.; Pattiaratchi, C.; Badal, R.; Synolakis, C.; Kânoğlu, U. A new tool for inundation modeling: Community modeling interface for tsunamis. Pure Appl. Geophys. 2011, 168, 2121-2131.

48. Marzocchi, W.; Lombardi, A A double branching model for earthquake occurrence. J. Geophys. Res. 2008, 113, B08317.

49. Tinti, S.; Maramai, A.; Graziani, L. The new Catalogue of Italian Tsunamis Nat. Haz. 2004, 33, 439-465.

50. Helmstetter, A.; Kagan, Y.Y.; Jackson, D.D. Comparison of short-term and time-dependent earthquake forecast models for Southern California. Bull. Seism. Soc. Am. 2006, 96, 90-106.

51. Papadopoulos, G.A. Tsunami hazard in the eastern Mediterranean: strong earthquakes and tsunamis in the Corinth Gulf, Central Greece. Nat. Haz. 2003, 29, 437-464.

52. Basili, R.; Valensise, G.; Vannoli, P.; Burrato, P.; Fracassi, U.; Mariano, S.; Tiberti M.; Boschi, E. Database of individual seismogenic sources (DISS), version 3: Summarizing 20 years of research on Italy's earthquake geologys. Tectonophysics 2008, 20-43.

53. Wells, D.L.; Coppersmith, K.J. New empirical relationships among magnitude, rupture length, rupture width, rupture area and surface displacement. Bull. Seismol. Soc. Am. 1994, 84, 974-1002.

54. Ascione A.; Caiazzo C.; Cinque A. Recent faulting in Southern Apennines (Italy): Geomorphic evidence, spatial distribution and implications for rates of activity. Boll. Soc. Geol. Ital. (Ital. J. Geosci.) 2007, 126, 293-305.

55. Galadini F.; Meletti C.; Vittori E Major active faults in Italy: Available surficial data. Neth. J. Geosci. 2001, 80, 273-296.

56. Okada, Y. Internal deformation due to shear and tensile faults in a half-space. Bull. Seismol. Soc. Am. 1982, 82, 1018-1040.

57. Kamigaichi, O. Tsunami forecasting and warning. In Encyclopedia of Complexity and System Science; Springer: New York, NY, USA, 2009; pp. 9592-9617.

58. Gutenberg, B.; Richter, C. Seismicity of the Earth and Associated Phenomena, 2nd ed.; Princeton University Press: Princeton, NJ, USA, 1954.

59. Cinque, A.; Ascione, A.; Caiazzo, C. Distribuzione spazio-temporale e caratterizzazione della fagliazione quaternaria in Appennino meridionale. Volume: Le ricerche del GNDT nel campo della pericolosita' sismica (1996-1999). A cura di Galadini 2003, 160, 1-16.

60. DISS-Working-Group. Database of individual seismogenic sources (DISS), version 3.1.1: A compilation of potential sources for earthquakes larger than M 5.5 in Italy and surrounding areas. INGV 2010 - Istituto Nazionale di Geofisica e Vulcanologia - All rights reserved; Doi:10.6092/INGV.IT-DISS3.1.1. Available online: http://diss.rm.ingv.it/diss/ (accessed on 1 March 2012).

61. Masson, D.; Harbitz, C.; Wynn, R.; Pedersen, G.; Lovholt, F. Submarine landslides: processes, triggers and hazard prediction. Phil. Trans. R. Soc. A 2006, 364, 2009-2039.

62. Martel, S. Mechanism of landslide initiation as a shear fracture phenomenon. Mar. Geol. 2004, 203, 319-339. 
63. Biscontin, G.; Pestana, J.; Nadim, F. Seismic triggering of submarine slides in soft cohesive soil deposits. Mar. Geol. 2004, 354, 203-341.

64. Booth, J.; Sangrey, D.; Fugate, J. A nomogram for interpreting slope stability of fine-grained deposits in modern and ancient marine environments. J. Sediment Petrol. 1985, 36, 29-36.

65. Kastens, K.; Mascle, J.; Auroux, C.; Bonatti, E.; Broglia, C.; Channel, J.; Curzi, P.; Emeis, K.; Glacon, G.; Hasegawa, S.; et al. ODP leg 107 in the Tyrrhenian Sea: Insights into passive margin and back-arc basin evolution. Geol. Soc. Am. Bull. 2012, 7, 1140-1156.

66. Biscontin, G.; Pestana, J.M. Factors affecting seismic response of submarine slopes Nat. Haz. Earth Syst. Sci. 2006, 6, 97-107.

67. Murty, T.S. Tsunami wave height dependence on landslide volume. Pure Appl. Geophys. 2003, 160, 2147-2153.

68. Calvari, S.; Spampinato, L.; Lodato, L.; Harris, A.L.; Patrick, M.; Dehn, J.B.; Andronico, D. Chronology and complex volcanic processes during the 2002-2003 flank eruption at Stromboli volcano (Italy) reconstructed from direct observations and surveys with a handheld thermal camera. J. Geophys. Res. 2005, 110, B02201.

69. Fabbri, A.; Gallignani, P.; Zitellini, N. Geologic Evolution of the Peri-Tyrrhenian Sedimentary Basins; Wezel, F.C., Ed.; Sedimentary basins of the Mediterranean margins, Technoprint: Bologna, Italy, 1981; pp. 101-126.

70. Grilli, S.T.; Watts, P. Tsunami generation by submarine mass failure. I: Modeling, experimental validation, and sensitivity analyses. J. Waterway Port Coast. Ocean Eng. 2005, 131, 283-297.

71. Watts, P.; Grilli M.; Tappin, D.R.; Fryer, G.J. Tsunami generation by submarine mass failure. II: Predictive equations and case studies. J. Waterway Port Coast. Ocean Eng. 2005, 131, 298-310.

72. Synolakis, C.E. The run-up of solitary waves. J. Fluid Mech. 1987, 185, 523-545.

73. Selva, J.; Orsi, G.; di Vito, M.; Marzocchi, W.; Sandri, L. Probability hazard map for future vent opening at the Campi Flegrei caldera, Italy. Bull. Volcanol. 2012, 74, 497-510.

74. Milia, A.; Torrente, M.; Giordano, F. Gravitational instability of submarine volcanoes offshore Campi Flegrei (Naples Bay, Italy). In Volcanism in the Campania Plain: Vesuvius, Campi Flegrei and Ignimbrites; De Vivo, B., Ed.; Elsevier, Developments in Volcanology, Universita' di Napoli Federico II: Naples, Italy, 2006; pp. 69-83.

75. de Alteriis, G.; Insinga, D.; Morabito, S.; Morra, V.; Chiocci, F.; Terrasi, F.; Lubritto, C.; di Benedetto, C.; Pazzanese, M. Age of submarine debris avalanches and tephrostratigraphy offshore Ischia Island, Tyrrhenian Sea, Italy. Marine Geol. 2010, 278, 1-18.

76. Della Seta, M.; Marotta, E.; Orsi, G.; de Vita, S.; Sansivero, F.; Fredi, P. Slope instability induced by volcano-tectonics as an additional source of hazard in active volcanic areas: The case of Ischia Island (Italy). Bull. Volcanol. 2012, 106, 74-79.

77. Kagan, Y. Likelihood analysis of earthquake catalogues. Geophys. J. Int. 1991, 106, 135-148.

78. Kagan, Y.; Knopoff, L. Stocastic synthesis of earthquake catalogues. Geophys. J. Int. 1981, 86, 2853-2862.

79. Ogata, Y. Statistical models for earthquake occurrences and residual analysis for point processes. J. Am. Statist. Assoc. 1988, 83, 9-27. 
80. Ogata, Y. Space-time-point-process for earthquake occurence. Ann. Inst. Statist. Math. 1998, 50, 379-402.

81. Console, R.; Murru M.; Lombardi, A. Refining earthquake clustering models. J. Geophys. Res. 2003, 108, 2468-2473.

82. Lombardi, A.M.; Marzocchi, W. Evidence of clustering and non-stationarity in the time distribution of large worldwide earthquakes. J. Geophys. Res. 2007, 112, B02303.

83. Omori, F. On the aftershocks of earthquakes. J. Coll. Sci. Imp. Univ. Tokio 1894, 7, 111-120.

84. Utsu, T. A statistical study on the occurrence of aftershocks. Geophys. Mag. 1961, 30, 521-605.

85. Lombardi, A.M.; Marzocchi, W. The ETAS model for daily forecasting of Italian seismicity in the CSEP experiment. Ann. Geophys. 2010, 53, 3.

86. Chiocci, F.L.; de Alteriis, G. The Ischia debris avalanche: First clear submarine evidence in the Mediterranean of a volcanic island prehistorical collapse. Terra Nova 2006, 18, 202-209, doi:10.1111/j.1365-3121.2006.00680.x.

87. Tinti S.; Chiocci F.L.; Zaniboni F.; Pagnoni G.; de Alteriis G. Numerical simulation of the tsunami generated by a past catastrophic landslide on the volcanic Island of Ischia, Italy. Mar. Geophys. Res. 2011, 32, 287-297, doi:10.1007/s11001-010-9109-6.

88. Okal, E.A.; Synolakis, C.E. Source discriminants for near-field tsunamis. Geophys. J. Int. 2004, 158, 899-912.

(c) 2015 by the authors; licensee MDPI, Basel, Switzerland. This article is an open access article distributed under the terms and conditions of the Creative Commons Attribution license (http://creativecommons.org/licenses/by/4.0/). 